CHAPTER 4

\title{
Public Innovation and Organizational Legitimacy: An Empirical Analysis of Social Media in the Dutch Police
}

\author{
Albert Meijer* \\ Utrecht School of Governance, The Netherlands
}

\begin{abstract}
This chapter aims to enhance our understanding of the relation between public innovation and organizational legitimacy. On the basis of the literature, we formulate the expectation that top-down innovation results in strengthening of a bureaucratic logic to producing legitimacy whereas bottom-up innovation results in more emphasis on a network logic. To investigate this expectation empirically, the chapter analyses the introduction and use of social media by the Dutch police. The outcomes challenge the expected relation: top-down innovation resulted in a more networked arrangement for legitimacy. We explain this finding by pointing out that the innovation process was infrastructural and empty in content: the content was provided through bottom-up innovation. We conclude that combinations of top-down and bottom-up practices can form a conceptual lens for studying the involvement of different organizational actors in processes of public innovation.
\end{abstract}

Keywords: Public innovation, organizational legitimacy, police, social media.

\section{INTRODUCTION}

Technological innovation in the public sector enables new forms of coordination and execution of work processes. The introduction of information and communication technologies in the public sector has been studied since the 1980s and this had resulted in an understanding of the transformative effects of these technological innovations (for example: Van de Donk \& Snellen, 1998; Fountain, 2001; Bekkers \& Homburg, 2007). Previous research highlights that large-scale technological systems are generally implemented from a system's perspective on organizations with the objective of rationalizing coordination and optimizing management control. A fascinating feature of our current times is that the new technologies, social media, contain a different script and put an emphasis on

\footnotetext{
*Corresponding author Albert Meijer: Utrecht School of Governance, The Netherlands; E-mail: a.j.meijer@uu.nl
} 
individual persons - public professionals, civil servants, police officers, etc. working within these organizational systems. To enhance our understanding of this new wave of technological and organizational innovation, this chapter studies the introduction of social media by the Dutch police.

We need to open the black box of social media innovation to understand the resulting positioning of social media communications in public organizations (Bekkers et al., 2011a; Meijer, 2013). This chapter investigates how organizational contexts shape the use of new technologies, and how new technologies in turn transform the organizations in which they are introduced. The underlying assumption is that the direction of the innovation process is of key importance for the outcome of the innovation processes. New technologies have certain characteristics but how these characteristics are connected to organizational practices depends on the process of innovation (Orlikowski, 1992). Organizational actors frame the new technological innovation in the organization and determine how this innovation is to be embedded in the organization. The dynamics of innovation are studied to understand how the proliferation of social media use in public organizations brings about institutional change.

This chapter focuses on innovation processes in the police. The police have continuously been at the forefront of adopting new technologies to strengthen the quality of their work. Formal information systems play a key role in police reporting but also in providing them with instruction and formal work planning. Stol (1996) has emphasized that these systems are used to strengthen organizational control over the work of police officers. These systems are also used for communication with professional peers but this type of communication has been structured according to a bureaucratic logic. Information systems for contacts with citizens were lacking but recently community police officers - like many other public officials (Mergel, 2013) - have started to use social media for communication with citizens. Social media as an infrastructural innovation forms the focal point for this study.

External communication plays a key role in the production of legitimacy and that is why government organizations have professionalized this function to embed it in a centralized system of control. The central research question in this paper is: how does the introduction of social media as an organizational innovation transform police-citizen relations and thus alter the production of police legitimacy? This paper conceptualizes the production of legitimacy as a combination of two logics: a bureaucratic logic and a network logic. These logics 
are continuously being renegotiated and the introduction of new media influences these negotiation processes. The paper proposes that the way new media are introduced in the organization - through top-down or bottom-up innovation processes - influences the balance between these logics. The empirical material demonstrates how processes of innovation can be emergent rather than planned and controlled and how, rather than being distinct forms, top-down and bottom-up innovation are combined. The case confirms that the evolving patterns of social media usage are not determined by technological characteristics but contingent upon the specific nature of the innovation processes that occur when new communication technology is introduced into public organizations.

This research contributes to our academic understanding of the relation between innovation processes and organizational arrangements for legitimacy. Much research focuses on the contribution of innovation to the effectiveness of organizations and, while it has been acknowledged that innovation is also a means to strengthen organizational legitimacy (Verhoest, et al., 2007), the relation between the form of the innovation process - top-down versus bottom-up innovation - and the resulting organizational arrangement for legitimacy has not yet been analyzed. The chapter highlights that qualitative empirical studies that trace and map the innovation processes are crucial for understanding how social media use in public organizations transform the way in which public legitimacy is produced.

This chapter first presents a theoretical framework that builds upon the literature on public innovation (paragraph 2) and on organizational arrangements for legitimacy (paragraph 3) to develop a model for the relation between innovation and organizational legitimacy (paragraph 4). Second, it will present the methods that have been used to investigate this relation in the specific case of social media innovation by the Dutch police (paragraph 5). Third, the findings of this empirical research are presented and analyzed to see what we can learn from this case about the relation between innovation and organizational arrangements for legitimacy (paragraph 6). The chapter ends with conclusions and suggestions for further research (paragraph 7).

\section{PROCESSES OF PUBLIC INNOVATION: BOTTOM-UP \& TOP-DOWN}

Public innovation had attracted more attention from both scholars and practitioners since the 1990s (Altshuler \& Behn 1997; Walker 2006 Bekkers et al. 2011a; Sørensen \& Torfing 2011). The basic idea behind public innovation is that processes of change in the public sector do not only take place through electoral 
renewal but also through processes of organizational learning and adaptation (Bernier \& Hafsi, 2007). Public organizations came to develop organizational structures and positions for public innovations and resources were increasingly made available. Technological innovation in the public sector has existed for many years but has evolved from a practice in selected organizations (tax departments, military organizations, the police, engineering departments) to become prominent with the introduction of personal computers in eventually all organization the public sector (Van de Donk \& Snellen, 1998).

Most research on public sector innovations focuses on the innovation of public policies, products, services, organizational structures and processes (Osborne \& Brown, 2005; Hartley, 2005). Social media innovation should be regarded as an infrastructural innovation (Lyytinen \& Rose, 2003) in the sense that it provides new opportunities to develop new services, products, processes, etc. One can compare this to an infrastructure such as a railroad system: the railroad provides opportunities for passenger transport and freight transport but these service innovations can only be developed if a railroad system has been built. Social media can be used to create more government transparency, to stimulate citizens' participation and to facilitate network collaboration, opening up opportunities for further policy, strategic or governance innovation (Hartley, 2005).

Innovation is conceptualized here as planned change (Osborne \& Brown, 2005). The basic idea is that public organizations can plan required change in response to or anticipation of changes in the environment or new opportunities. These changes can be either incremental or transformational and especially the latter type of change has triggered much interested both in the academic community and among practitioners (Osborne \& Brown, 2005). This chapter follows Bekkers et al. $(2011 \mathrm{~b}, 197)$ who define innovation as "a learning process in which governments attempt to meet specific societal challenges". The aspiration is that innovative change can help to adapt government organizations to changing environments.

Innovations are both developed in organizations and adopted from other organizations. Most often, innovations in organizations are adaptations of innovations that have been developed elsewhere. Processes of adaptation and innovation are often described in the form of phase models (Damanpour 1991; Oliver, 2000; Meijer, 2013). We can make a distinction between idea generation, idea testing, idea scaling-up and idea diffusion. Certain actors introduce the idea of using new technologies to strengthen organizational processes (idea generation) 
and, after small-scale experiments with use of the new technologies (idea testing), the technology is rolled out in the organization (idea scaling-up and idea diffusion). Different actors are involved in these stages and the different barriers need to be tackled to bring the innovation process to a successful end.

The process of technological innovation entails more than simply using a new piece of technology. The New Medium Studies (Deibert, 1997; Hutchby, 2001, 2003) highlights that new media have certain characteristics that do not determine but enable certain communication patterns. Sellen \& Harper $(2002,17,18)$ define an affordance as follows: "An affordance refers to the fact that the physical properties of an object make possible different functions for the person perceiving or using that object". The affordances of new technologies are to a certain degree determined by processes of technological construction that take place outside of the organization (Orlikowski, 1992). This means that, in a study of the impacts of social media on the role of community police officers, we need to analyze which functions are being attributed to social media by police organizations in innovation processes. The dynamics of the innovations - the cognitive, normative and strategic interactions between various actors- determine how the technology is constructed and used in organizational practices.

To understand the affordance that is attributed to a new technology, we need to study the process of innovation within an organization. The introduction of social media and the attribution of function to these media can occur through top-down or bottom-up processes of innovation (Hesselbein, Goldsmith \& Sommerville, 2001; Borins, 2002). Top-down innovation refers to innovation processes that start at the central - management or staff - level. The work floor is asked persuaded, stimulated, forced - to use the innovation and managing innovation is to a large extent about managing this change process. Bottom-up innovation originates from frontline staff and is based upon their efforts to improve practices and their knowledge about the work situation. Success depends on the extent to which management picks up these forms of innovation and stimulates their diffusion in the rest of the organization. The crucial difference is that top-down innovation takes place from the perspective of the organization as a system and translates system-level analyses into individual actions while the bottom-up perspective takes individual actions as a starting point and views the organizational interest as an aggregation of individual actions (see Table 1). 
Table 1: Two types of innovation processes

\begin{tabular}{|l|l|l|}
\hline & Top-down Innovation & Bottom-up Innovation \\
\hline Origin & Central level & Work floor \\
\hline Focus & Improving the organization & Improving work floor practices \\
\hline Key to success & Support on work floor & Attention from management \\
\hline
\end{tabular}

The literature on innovation in the police concerns new methods for police investigations such as data analysis and DNA techniques but also the use of technology for organizational steering (Mullen, 1996; Schneider et al., 2008). The large scale information systems that were introduced in the police - and other government organizations - from the 1990s on were mainly introduced from a top-down perspective (Stol, 1996). Bottom-up innovation played a much bigger role in the introduction of e-mail in public organizations and individual employees played an important role in the assignment of function to this new technology (Meijer, 2008). The direction of the innovation process matters since it means that different affordances can be assigned to the technology in the process of innovation and these affordances matter, among other things, for the organizational production of legitimacy.

\section{BUREAUCRATIC OR NETWORKED PRODUCTION OF LEGITIMACY}

Organizational legitimacy is crucial to the continued existence of the organization and, therefore, the production of legitimacy has received much attention both by academics and practitioners. It is also a much debated concept that has been conceptualized in many different ways. This papers follows the much-cited definition of legitimacy by Suchman (1995, 574): "Legitimacy is a generalized perception or assumption that the actions of an entity are desirable, proper, or appropriate within some socially constructed system of norms, values, beliefs, and definitions". Police legitimacy can arise from perceptions of the procedures of the police but also from the outcome of their work (cf. Tyler, 2004). Perceptions of police work are formed through personal experiences and personal contacts with the police but also through stories from others and stories in the media. In both cases the organization of and communication over police work play a crucial role in forming the perceptions and, hence, they are important instruments for the production of police legitimacy (Elsbach, 1994).

Power (2003) highlights that public organizations have various systems to produce legitimacy. These consist both of internal arrangements such as accounting and recordkeeping and external arrangements such as transparency 
and accountability. Overall, two dominant logics have been identified in the organizational production of police legitimacy: a bureaucratic and a networked logic (cf. Powell, 1990; Meijer, 2008). ${ }^{1}$ The bureaucratic logic builds upon the idea that vertical control of the police organization and embedding it in a system of democratic and representative government are crucial to police legitimacy while the networked logic highlights that direct interactions between (community) police officers and societal actors - actual encounters - produce organizational legitimacy. The bureaucratic argument basically states that individual police officers are legitimate since the organization is legitimate while the network logic highlights that it is the other way around: the police organization derives its legitimacy from the legitimacy of the individual police officers.

The bureaucratic logic is based upon Weberian ideas about government organizations. The organizational logic is about the contributions of individual employees to the attainment of organizational objectives. Employees are wheels in a machine and these wheels should be adjusted to the machine's overall desired outputs. A central problem of organization is how to deal with centrifugal tendencies, i.e. mechanisms that undermine the unity of organization (Kaufman, 1960). Organizations develop objectives but need these to be enacted by employees to be realized (cf. Kaufman, 1960). Employees may have various reasons to act in a different manner and therefore organizations develop a range of mechanisms to ensure that employees act in accordance with organizational objectives. The objectives and policies are developed in response to political and public demands that result in priority settings and choices in the allocations of scarce resources. Garland $(2001,18)$ emphasizes that the new managerialism in policing has narrowed professional discretion and tightly regulated working practice.

In some organizations, the organizational logic may leave little leeway for situational reasoning but in so-called street-level bureaucracies the acting bureaucrats have a certain degree of autonomy (Lipsky, 1980). For practical reasons, the behavior of community officer cannot be determined fully by organizational rules and procedures. This results in instructions for street-level police officers that are based on an organizational logic but that creates a certain room for applying this in a specific situation. This means that the realization of organizational objectives does not only depend on structures and procedures but also on the way street-level bureaucrats act in a specific (underdetermined)

${ }^{1}$ Other logics may be important in other sectors. A professional logic is, for example, of crucial importance to producing legitimacy in healthcare and a market logic may be of crucial importance in a sector such as public housing. 
situation. Lipsky (1980) emphasizes that street-level bureaucrats such as police officers play a key role in actually realizing the policy.

That leaves us with the question how street-level bureaucrats can produce police legitimacy if they make decisions not prescribed by the hierarchy. Based on Lipsky (1980) their production of legitimacy can be conceptualized as more personal and situated. The horizontal logic of networked contacts with societal actors forms a complementary mechanism to the vertical logic of the bureaucracy. Several mechanisms play a role here such as which societal actors manage to establish contacts with the community police officers, how clearly they express their demands and how sensitive the police officer is to these demands. The nature of community networks plays a key role in the demand articulation of customers of community police officers (Trojanowicz \& Bucqueroux, 1990).

This discussion of the literature shows that two complementary and sometimes competing logics play a role in the production of police legitimacy. ${ }^{2}$ These logics rely on different modes of communication (cf. Meijer, 2008). The bureaucratic logic is based upon the idea of centralized external communication and a focus on issues that are of relevance to the whole organization in the external communications. The networked logic, in contrast, focuses on fragmented, individualized external communication and a focus on issues that are of specific importance to police officers and the setting in which they work. These two logics are summarized in Table 2.

Table 2: Logics for the production of police legitimacy

\begin{tabular}{|c|c|c|}
\hline & Bureaucratic Logic & Network Logic \\
\hline Focus of legitimacy & Legitimacy of police organization & $\begin{array}{l}\text { Legitimacy of individual police } \\
\text { officer }\end{array}$ \\
\hline Key argument & $\begin{array}{l}\text { Police officer is legitimate since } \\
\text { he is a member of a legitimate } \\
\text { organization }\end{array}$ & $\begin{array}{l}\text { Police organization is legitimate } \\
\text { since its members are legitimate }\end{array}$ \\
\hline $\begin{array}{l}\text { Dimension } 1 . \\
\text { Control over external } \\
\text { communication }\end{array}$ & $\begin{array}{l}\text { Communications department } \\
\text { determine external } \\
\text { communications. }\end{array}$ & $\begin{array}{l}\text { Individual police officers have } \\
\text { leeway for external } \\
\text { communications. }\end{array}$ \\
\hline $\begin{array}{l}\text { Dimension } 2 . \\
\text { Content of external } \\
\text { communication }\end{array}$ & $\begin{array}{l}\text { Global issues of relevance to all } \\
\text { citizens within the police } \\
\text { department. }\end{array}$ & $\begin{array}{l}\text { Local issues of relevance to the } \\
\text { citizens in a specific } \\
\text { neighbourhood. }\end{array}$ \\
\hline
\end{tabular}

\footnotetext{
${ }^{2}$ The introduction of community police officers is, by itself, a means to strengthen the network logic in the production of police legitimacy and complement the bureaucratic logic. The basic idea is that police legitimacy is strengthened by creating short, direct connections between individual police officers and citizens. In a way, this transforms the police organization from an inaccessible bureaucratic organization to a more accessible network of police professionals.
} 
This brief summary of debates about the production of government legitimacy provides some building blocks for our analysis of the impact of social media. The two logics complement each other but may also result in tensions. Temporary balances in these logics are socially constructed and reconstructed in what is regarded as the correct way to produce police legitimacy. This temporary balance may be challenged by the introduction of social media as an organizational innovation in the police.

\section{EXPECTED RELATIONS BETWEEN INNOVATION \& LEGITIMACY}

On the basis of this exploration of theories of media affordances and innovation, this chapter proposes that the nature of the innovation process will determine the resulting effect of social media use on the organizational production of legitimacy (cf. Orlikowski, 1992). Social media create opportunities to strengthen external communication with citizens but these opportunities may be used and embedded in the organization in different ways. Social media can either be used to strengthen a bureaucratic logic or a network logic to producing legitimacy. Previous research into the introduction of new technologies in government organizations has identified the mechanism that those that control the innovation process will use it to strengthen their own position (Danziger et al., 1982; Kraemer \& King, 2006). This would mean that centrally controlled innovation would result in a strengthening of a bureaucratic logic to producing legitimacy whereas control over the innovation process at the work floor - bottom-up innovation - would result in a strengthening of the network logic.

Previous research highlights that technologies such as databases and workflow systems were mainly introduced through top-down innovation and this resulted in a stronger bureaucratic logic in the production of legitimacy (Zuurmond, 1994; Stol, 1996; Jorna, 2009). These systems were used to strengthen the bureaucratic organization and exert more control over street-level bureaucrats. These studies did not explicitly address the question how these systems change the organizational arrangement for legitimacy but the case descriptions of these studies into social benefit agencies (Zuurmond, 1994), the police (Stol, 1996) and government subsidies (Jorna, 2009) clearly highlight that these systems strengthen the bureaucratic logic of producing legitimacy.

Previous studies almost exclusively focused on large scale technological systems. A key feature of these systems is that they are expensive and need to be designed and developed to fit organizational processes (Zuurmond, 1994; Jorna, 2009). Social media have different features since they are readily available and can be 
used without much training or support. No heavy technological infrastructure is needed to make these technologies work. Basically, this technology has been developed for the consumer market and not for use within organizations. These features make social media rather different from the database and workflow systems that have been studied before and this new wave of technological innovations in the public sector demands attention since little is known about the way as these technologies are introduced within organization.

One previous study focused on social media strategies of police organizations and also touched upon the way social media were introduced within the organization (Meijer \& Thaens, 2013). This study of three North American police departments - Toronto, Boston and Washington DC - showed variation. While social media innovation started at the work floor in Toronto, the police departments in Boston and Washington DC introduced social media through a process of top-down innovation. Meijer and Thaens (2013) describe how the police departments in Boston and Washington DC opted for a centralization of external communications while Toronto developed a decentralized system with community police officers as external communicators. That study did not focus on the organizational arrangement for legitimacy but it does highlight that police department follow different innovation trajectories in their implementation of social media and these trajectories seem to result in different organizational arrangements for external communications.

To enhance our knowledge of the relation between social media and the production of legitimacy, the relation between the innovation process and the resulting arrangement for organizational legitimacy is explored through empirical research in the Netherlands. The research aims to find out what types of innovation take place in police organizations, what the resulting effects are on the production of police legitimacy and whether the assumed theoretical relations are confirmed in these findings.

\section{RESEARCH DESIGN AND METHODS}

Public innovation is studied as the process by which social media are being incorporated and used in the police for supporting specific tasks and functions. Top-down innovation is concluded to take place when the attribution of function is steered by formal policy guidelines for the use of social media and the diffusion of social media in the organization depends on central decisions about resources for social media (i.e. smart phones for police officers). Bottom-up innovation is 
observed when the use of social media is initiated by community police officers and its use spreads through the organization by example (i.e. horizontal diffusion).

The role of social media in the organizational production of police legitimacy is operationalized as follows:

The bureaucratic logic is reflected in the use of social media for centralized communications. Social media are predominantly used at the central level for external communications. The messages communicated to the audience mainly contain content of general interest to all citizens in the police department.

The networked logic is reflected in the use of social media for decentralized communications. Community police officers use social media to create individual communication channels with society. The messages communicated to the audience mainly contain content of specific interest to citizens in a neighborhood or small town.

The research focuses on the use of Twitter by the Dutch police. Twitter is a freely available social networking and microblogging tool that can be used to post messages in 140 characters. Tweets are publicly visible by default and followers see these messages in their timeline. In contrast with Facebook, relations on Twitter are asymmetrical: one can follow another person without being followed by that person. Twitter is the most popular social medium for professional communication and its use has spread rapidly within the Dutch police since 2009 (Meijer et al., 2013).

The use of Twitter and its effects were investigated in four police departments in the Netherlands. We will refer to them here by the main cities in these departments: The Hague, Utrecht, Apeldoorn and Eindhoven. ${ }^{3}$ These departments were selected on the basis of their level of social media use (all relatively high users) and differences in more urban and more rural environments. In view of the similarities between these departments in terms of formal structure and organizational culture, this is a most similar case design. The cases will be used to obtain an in-depth understanding of innovation dynamics in similar organizations.

In these departments, we used a combination of (mostly qualitative) methods to investigate the innovation process and the resulting organizational arrangement

\footnotetext{
${ }^{3}$ The official names for the police departments are Haaglanden, Utrecht, Gelderland-Noord-Oost en Brabant-Zuid-Oost.
} 
for legitimacy: interviews with one communication officer in each department, interviews with 20 community police officers, a quantitative analysis of the tweets of all community police officers in each department and a qualitative analysis of the tweets of all community police officers in each department. The results were used to analyze the process of innovation first and then analyze the impact of social media on the organizational production of police legitimacy.

\section{FINDINGS}

\section{Patterns of Innovation}

Twitter has been introduced in the Dutch police fairly recently. The introduction started around 2009 with a few individuals using Twitter without any policy guidelines or formal mandate to communicate about their police work. These individuals were being noticed by other departments and they told enthusiastic stories about the value of Twitter for supporting police communications. These enthusiastic stories raised interest in social media for police communications all around the country (Meijer et al., 2013).

The use of Twitter started at the communication departments of the four police departments in 2009 and 2010. These communication professionals informed police chiefs but did not ask for permission (and this was not needed because they did not require funding). The reasons for wanting to use Twitter differed to some extent. The Utrecht Police Department saw social media as a means to draw attention to a website that had been developed for informing citizens about crime in their neighborhood and asking for information about thefts and misdemeanors. Social media was seen as a pointer to more exhaustive information and that could help to draw the attention of citizens to this initiative. The Eindhoven Police Department started using Twitter to communicate press releases to a broader audience than just journalists. The The Hague Police Department started using Twitter for crowd control and used Twitter during the world cup football in 2010. Subsequently, they raised broader citizen interest by Twittering a selection of news releases. The Apeldoorn Police Department started with a central account with press releases and then split these up in press releases for local groups. In sum, all four police departments started with centralized information provision through Twitter and then came to realize that local information provided by community police officers could be of additional interest to citizens.

Subsequent innovation dynamics were highly similar in all four police departments. The initiatives were seen as successful and the communications departments decided to broaden up the use of social media to community police 
officers, often at the request of technology-savvy police officers. The communication professionals felt that citizens would be most interested in local information and therefore they developed the idea that community police officers should use Twitter for presenting information to citizens. The realization of this idea took some time because money had to be made available for financing PDAs for community police officers. When this money had been made available, community officers were asked whether they were willing to start using Twitter for communication with citizens. These requests were open in nature and the police officers had much autonomy in its use of Twitter in whatever way they deemed fit. A community police officer stated:

"There was a bottom line but above that the message was primarily: do your own thing, experiment with the new medium and use your professional knowledge and common sense to identify what can and what cannot be done".

Many community police officers were interested and the use of Twitter grew rapidly. Community police officers became interested because their colleagues were telling them enthusiastic stories about the new medium and the resulting interactions with citizens. Communications departments monitored the Twitter use of police officers and, if necessary, provided feedback to ensure that there would be no transgressions. In parallel, the communications department developed (brief and relatively open) guidelines for the use of Twitter. One police officer said the following:

"At a certain stage we ran into some situations that did not seem suitable for tweeting, sometimes in view of media coverage and sometimes because of not wanting to interfere with police investigations. Then we started to limit certain uses. This resulted in guidelines for police officers".

The development of formal policies meant that police officers that started to use Twitter later had more guidelines to regulate their usage of the new medium. But all communication departments except for the one in The Hague emphasized that the police officers could still use a personal touch in their Twitter communications.

The innovation processes in these four departments shows that, at the start, the driving force was the Communications Department. All police departments started with central accounts and only at a later stage were community police officers asked to provide local information. At that time, the community police officers obtained few instructions regarding the content of the information to be communicated through Twitter. They could use the medium as they saw fit. Guidelines for use by 
community police officers evolved later. One cannot conclude that the process of innovation evolved in a bottom-up manner since communication departments drove the introduction of social media in the four police departments. Nevertheless, community police officers had much leeway in exploring the possible uses of the new medium and in developing patterns of use that they regarded as appropriate. The top-down innovation was rather empty in content: an infrastructure was provided but individual users further developed the use of that infrastructure. The communication departments only came to provide some guidelines at a later stage. Social media innovation in the Dutch police can be characterized as an interactive relation between top-down and bottom-up innovation.

\section{Social Media and the Two Logics of Producing Legitimacy}

The two dimensions of the production of legitimacy - control over external communications and content of communication - will now be used to structure our empirical findings and explore how social media usage affects the organizational production of police legitimacy.

A first difference between the bureaucratic and the network logic is the organization of external communication. If the use of Twitter in these police departments would take the form of the bureaucratic logic, Twitter would be used for communications controlled by the communications department: they would use the new medium to develop an additional channel of communication with citizens. Leeway for external communication for the individual police officers would reflect the network logic since the communications department would be able to regulate but not control these communications. Which logic did we find?

The numbers of central Twitter accounts - run by the communications department - and Twitter accounts of community police officers are presented in Table $\mathbf{3}$.

Table 3: Central and individual Twitter accounts in the four police departments

\begin{tabular}{|l|l|l|l|l|}
\hline & $\begin{array}{l}\text { Number of } \\
\text { central Twitter } \\
\text { accounts }\end{array}$ & $\begin{array}{l}\text { Number of followers } \\
\text { central Twitter } \\
\text { account }\end{array}$ & $\begin{array}{l}\text { Number of } \\
\text { individual Twitter } \\
\text { accounts }\end{array}$ & $\begin{array}{l}\text { Total number of } \\
\text { followers of the } \\
\text { individual Twitter } \\
\text { accounts }\end{array}$ \\
\hline Eindhoven & 4 & 7,629 & 31 & 22,348 \\
\hline The Hague & 1 & 20,350 & 87 & 41,541 \\
\hline Apeldoorn & 2 & 6,604 & 72 & 38,257 \\
\hline Utrecht & 3 & 21,540 & 28 & 24,660 \\
\hline
\end{tabular}

The table shows that there are many more Twitter accounts at the community police officer level than at the central level. In total there are more than 20 
accounts of community police officers for each central Twitter account. These central Twitter accounts tend to have more followers - even over 20,000 for the central account of the The Hague Police Department - but added together the accounts of community police officers have more followers in all four police departments.

These findings highlight that the communications department have control over the most followed Twitter accounts but community police officers have considerable leeway to use Twitter and they have been able to attract a high number of followers. This indicates that the bureaucratic logic is reproduced in the control over the organizational and most followed Twitter accounts. However, the network logic seems to make more use of the opportunities of the new medium to communicate with citizens by using it to generate a fragmented but overall larger audience for social media communications. No differences between the four police departments were found.

A second difference concerns the content of the communication. The bureaucratic logic emphasizes the use for issues that are of interest to all citizens in the area of the police department while the network logic emphasizes content that is of relevance for the local neighborhood.

The central account is mostly - about one third of the messages - used for asking citizen for information related to crimes or to missing persons. In addition, the police frequently tweets successes (about one quarter of the tweets). They inform citizen about criminals that have been apprehended. A third major group is messages related to prevention or general citizen information. The following tweets are examples of communications at the central account level:

"Arrested: man suspected of hitting and kicking a girl in [the town of] \#lopik. Arrested on May 2 nd". (Utrecht, 3 May 2012)

"Dutch coffee shops will be private clubs only accessible for Dutch citizens' http://www.new-rules.eu/newrulesnl”' (Eindhoven, 4 May 2012)

We have also asked the community police officers to highlight the functions of Twitter. Three functions were mentioned consistently by the community police officers: show what community police officers do, obtain information from citizens and strengthening community networks. The following Tweets present some examples: 
"About to have a meeting with the city about our approach of youth groups in [the neighborhood of] \#hoograven! Any ideas? \#dtv Henkg" (Utrecht, 19 April 2012).

"Report of beer theft at [local supermarket] in goylaan. Nice footage! Now we need to find the perpetrators. [the neighborhood of] \#hoograven best robv" (Utrecht, 18 April 2012).

We found some distinction between the centralized accounts and the tweets of community police officers but the difference was not as was expected. Centralized accounts also focus on local issues but they tend to only tweet issues that are of major importance (violent crimes) while the community police officers also tweet about crimes with less impact (beer theft from supermarket) and even local meetings. The difference, however, should not be exaggerated. Central accounts and Twitter accounts of community police officers also regularly retweet each other's tweets. The findings still illustrate that the local network logic results in more minor news for citizens related to their own neighborhood. It also results in a different perspective on policing since not only high-impact issues are communicated but also normal police work.

The findings show that social media are primarily used for strengthening the networked logic of community police officers. Most Twitter accounts are run by community police officers and these accounts have more followers than central accounts. The content of central and community officer accounts has similarities but central accounts tend to focus more on larger issues whereas trivialities are also presented in community police officers accounts. Overall this shows that the use of Twitter strengthens the networked production of legitimacy more than the hierarchical production.

\section{Process of Innovation and Resulting Organization Arrangement for Legitimacy}

Combining the analysis of the innovation process and the changes in the production of legitimacy, we found that there is a facilitated process going on, whereas the top does not dictate what should be done at the bottom, but rather initiates the process and provides the infrastructure needed for the innovation process to develop. Community police officers were - and are - encouraged to use social media to communicate with citizens. The push was open in nature and gave them much autonomy to develop their own patterns of usage albeit that they are to 
some extent being monitored by communication professionals and guidelines are provided to indicate what they can and cannot do with Twitter.

The resulting organizational arrangement for legitimacy is mostly in line with the networked logic. All police departments have more individual than central Twitter accounts and, even though these central accounts have on average many more followers, the number of followers of the central accounts is higher. The central accounts do sometimes communicate local issues but they tend to focus on larger issues whereas more trivial issues are only communicated through the accounts of community police officers. This highlights that the communication of more trivial local issues increases through the use of Twitter. The number of accounts and the content of the communications highlight that Twitter is mostly used to strengthen the networked production of legitimacy.

An analysis of the relation between innovation and the organizational arrangement for legitimacy challenges our expectations. The innovation process started top-down and the central communications department was in the lead and initially the new medium was primarily used to strengthen the bureaucratic logic. Subsequently, the communications department provided opportunities to community officers to frame the new medium according to their own needs and wants for communication with citizens. The top-down innovation became rather empty in the sense that the responsibility for the content was shifted to the community police officers. Still, the channel for strengthening the networked logic for legitimacy was provided by the central level. This indicates that the empty top-down innovation process resulted in a more networked production of legitimacy.

\section{CONCLUSION}

The empirical findings present interesting insights in the public innovation. A first insight was that infrastructural innovations generate new opportunities for communication but do not stipulate how these opportunities are to be used. Twitter is provided as a medium of communication to community police officers but few clear objectives and guidelines are presented to them. While previous information and communication technologies were developed to strengthen operational, service or control processes, there is no direct link between the introduction of the new innovation and its purposeful use within the organization. Uses of the infrastructure are developed in organizational practices rather than in explicit strategies. 
A second, related, insight is that public organizations may come to provide a new channel of communications - a new infrastructure - without an explicit strategy: the process of innovation is emergent. This emergent innovation shows many similarities to the diffusion of e-mails in public organizations (Meijer, 2008): police departments feel a public pressure to use new media and employees within the organization ask for the media (which they often already use privately). In response, the department creates the facilities for using social media but no objectives or guidelines are formulated. Individual employees are to put Twitter to their own use and, as a consequence, new practices are being constructed by community police officers in close connection with communication departments.

Thirdly, this study has provided important insights in the relation between topdown and bottom-up innovation in the public sector. The study shows that these two types of innovation can be combined rather than they are different forms. The study showed two ways of combining top-down and bottom-up innovation. The first one is a temporal combination: the innovation process had more of a topdown nature in the beginning when the communication department started to experiment with central Twitter accounts, gave ample room for bottom-up innovation at a later stage when community police officers could experiment with the new medium and, again, had some characteristics of a top-down process when the communication departments drafted guidelines for the use of Twitter. The second way of combining top-down and bottom-up innovation is a substantial one. The cases showed how an empty top-down innovation - the opportunity to use Twitter - was filled with content in a bottom-up process when community police officers started to develop communication practices. These combinations of top-down and bottom-up practices can form a conceptual lens for studying the involvement of different organizational actors in processes of public innovation.

Fourthly, the study highlighted that the evolving patterns of social media usage are not determined by technological characteristics. Even though the pattern of innovation was highly similar in all four Dutch police departments, these findings are different from what has previously been found in the Boston and Metropolitan (Washington DC) Police Departments (Meijer \& Thaens, 2013). The use of Twitter in those police departments resulted in a strengthening of bureaucratic patterns while the Dutch police departments used Twitter to strengthen their networked logic. Further comparative work is needed to understand these differences and to explore to what extent they result from cultural, institutional or process features of the innovation process. 
This exploratory study has identified the relation between innovation and legitimacy as an important research topic. While many studies pay attention to the legitimacy of innovations as a requirement for a successful innovation process (Hekkert et al., 2007), few studies evaluate how innovations change organizational arrangements for legitimacy. Legitimacy is a key value in public administration that plays an important role in the structure of public sector organizations. More research into this relation is crucial to advance our understanding of innovation in the public sector.

\section{ACKNOWLEDGEMENTS}

Declared none.

\section{CONFLICT OF INTEREST}

The author confirms that this chapter contents have no conflict of interest.

\section{REFERENCES}

Altshuler, A.A., \& Behn, R.D. (Eds.) (1997). Innovation in American Government. Washington, DC: Brookings Institution.

Bekkers, V., Edelenbos, J., \& Steijn, B. (Eds) (2011a). Innovation in the Public Sector. Linking Capacity and Leadership. Houndmills: Palgrave MacMillan.

Bekkers, V., Edelenbos, J., \& Steijn, B. (Eds.) (2011b). An innovative public sector? Embarking in the innovation journey. In: Bekkers, V., Edelenbos, J. \& Steijn, B. (Eds). Innovation in the Public Sector. Linking Capacity and Leadership. (pp. 197-221). Houndmills: Palgrave MacMillan.

Bekkers, V., \& Homburg, V. (2007). The myths of e-government: Looking beyond the assumptions of a new and better government. In The Information Society, 23:5, 373-382.

Bernier, L., \& Hafsi, T. (2007). The changing nature of public entrepreneurship. In Public Administration Review, 67:3, 488-503.

Borins, S. (2002). Leadership and innovation in the public sector. In Leadership \& Organization, 23:8, 467476.

Damanpour, F. (1991). Organizational innovation: A meta-analysis of effect of determinants and moderators. In Academy of Management Journal, 34:3, 555-90.

Danziger, J.N., Dutton, W.H., Kling, R., \& Kraemer, K.L. (1982). Computers and Politics. New York: Columbia University Press.

Deibert, R.D. (1997). Parchment, Printing and Hypermedia. New York: Columbia University Press.

Elsbach, K.D. (1994). Managing organizational legitimacy in the California cattle industry: The construction and effectiveness of verbal accounts. In Administrative Science Quarterly, 39:1, 57-88.

Fountain, J.E. (2001). Building the virtual state: Information technology and institutional change. Washington: Brookings Institution Press.

Garland, D. (2001). The Culture of Control. Crime and Social Order in Contemporary Societies. Chicago: The University of Chicago Press.

Hartley, J. (2005). Innovation in governance and public services: past and present. In Public Money \& Management, 25:1, 27-34.

Hekkert, M.P., Suurs, R.A.A., Negro, S.O., Smits, R.E.H.M., \& Kuhlmann, S. (2007). Functions of Innovation Systems: A new approach for analyzing technological change. In Technological Forecasting and Social Change, 74, 413-432. 
Hesselbein, F., Goldsmith, M., \& Somerville, I. (2001). Leading for Innovation. San Francisco, CA: JosseyBass.

Hutchby, I. (2001). Conversation and technology. From the telephone to the Internet. Cambridge (UK): Polity.

Hutchby, I. (2003). Affordances and the analysis of technologically mediated interaction: A response to Brian Rappert. In Sociology, 37, 581-589.

Jorna, F. (2009). De autobureaucratie. Informatisering en leren van uitvoering. Delft: Eburon.

Kaufman, H. (1960). The Forest Ranger: A Study in Administrative Behavior. Baltimore, MD: Johns Hopkins Press.

Kraemer, K.L., \& King, J.L (2006). Information technology and administrative reform: Will E-government be different? In International Journal of Electronic Government Research, 2:1, 1-20.

Lipsky, M. (1980). Street-level Bureaucracy; Dilemmas of the Individual in Public Services. New York: Russell Sage Foundation.

Lyytinen, K., \& Rose, G. (2003). Disruptive information system innovation: the case of internet computing. In Information Systems Journal, 13:4, 301-330.

Meijer, A.J. (2008). E-mail in government: Not post-bureaucratic but late-bureaucratic organizations. In Government Information Quarterly, 25:3, 429-447.

Meijer, A. (2012). Co-Production in an Information Age. In Pestoff, V., Brandsen T., \& Verschuere, B. (Eds.), New Public Governance, the Third Sector and Co-Production. New York/London: Routledge.

Meijer, A. (2013). New media and the coproduction of safety: An empirical analysis of dutch practices. In American Review of Public Administration. doi: 10.1177/0275074012455843.

Meijer, A., Grimmelikhuijsen, S.G., Fictorie, D., Thaens, M., \& Siep, P. (2013). Politie en sociale media: Van Hype naar onderbouwde keuzen. Amsterdam: Reed Business.

Meijer, Albert J. \& Marcel Thaens, (2013). Social media strategies: Understanding the differences between North American police departments. In Government Information Quarterly. 30:4, 343-350.

Mergel, I. (2013). Social media adoption and resulting tactics in the U.S. federal government. In Government Information Quarterly, 30:4, 123-130.

Mullen, K. (1996). The Computerization of Law Enforcement: a diffusion of innovation study. Doctoral Thesis. Albany: State University of New York.

Oliver, W.M. (2000). The third generation of community policing: moving through innovation, diffusion, and institutionalization. In Police Quarterly, 3:4, 367-88.

Orlikowski, W.J. (1992). The duality of technology: Rethinking the concept of technology in organizations. In Organization Science, 3:3, 398-427.

Osborne, S.P., \& Brown, L. (2005). Managing Change and Innovation in Public Service Organizations. Milton Park: Routledge.

Power, M. (2003). Auditing and the production of legitimacy. In Accounting, Organizations and Society, 28:4, 379-394

Powell, W.W. (1990). Neither market nor hierarchy: Network forms of organization. In Research in Organizational Behavior, 12, 295-336.

Schneider, M.C., Chapman, R., \& Schapiro, A. (2008). Towards the unification of policing innovations under community policing. Policing. In International Journal of Police Strategies and Management, 32:4, 694-718.

Sellen, A.J., \& Harper, R.H.R. (2002). The myth of the paperless office. Cambridge: MIT Press.

Sørensen, E., \& Torfing, J. (2011). Enhancing collaborative innovation in the public sector. In Administration and Society, 43:8, 842-68.

Stol, W.Ph. (1996). Politie-optreden en informatietechnologie. Over sociale controle van politiemensen. Lelystad: Koninklijke Vermande.

Suchman, M.C. (1995). Managing legitimacy: Strategic and institutional approaches. In Academy of Management Review, 20, 571-610.

Trojanowicz, R.T., \& Bucqueroux, B. (1990). Community Policing: A Contemporary Perspective. Cincinnati: Anderson Publishing Company.

Tyler, T.R. (2004). Enhancing police legitimacy. In The Annals of the American Academy of Political and Social Science, 593, 84-99.

Van de Donk, W.B., \& Snellen, I.T.M. (1998). Towards a theory of public administration in an information age?. In Public Administration in an Information Age, A Handbook, 3-19. 
Verhoest, K., Verschuere, B., \& Bouckaert, G. (2007). Pressure, legitimacy, and innovative behavior by public organizations. In Governance, 20:3, 469-497.

Walker, R.M. (2006). Innovation type and diffusion: An empirical analysis of local government. In Public Administration, 84:2, 311-35.

Zuurmond, A. (1994). De Infocratie, Een theoretische en empirische heroriëntatie op Weber's ideaaltype in het informatietijdperk [The infocracy. A theoretical and empirical re-orientation on Weber's idealtype in the Information Age]. Delft: Eburon. 